\title{
A representatividade de treinadoras do sexo feminino em uma competição oficial
}

\author{
The representation of female coaches in an official competition \\ La representación de entrenadoras en una competición oficial
}

Recebido: 10/08/2021 | Revisado: 22/08/2021 | Aceito: 25/08/2021 | Publicado: 27/08/2021

\author{
Matheus de Oliveira Jaime \\ ORCID: https://orcid.org/0000-0001-6320-667X \\ Universidade Estadual de Maringá, Brasil \\ E-mail: matheus.o.jaime@gmail.com \\ Mariana Ardengue \\ ORCID: https://orcid.org/0000-0001-9940-2664 \\ Universidade Estadual de Maringá, Brasil \\ E-mail: mariardengue39@gmail.com \\ Vanessa Andrade \\ ORCID: https://orcid.org/0000-0002-2729-3072 \\ Instituto Federal de Educação, Ciência e Tecnologia do Paraná, Brasil \\ E-mail: vanessa.andrade@ifpr.edu.br \\ Gustavo Borges Monteiro \\ ORCID: https://orcid.org/0000-0002-2353-1360 \\ Universidade Estadual de Maringá, Brasil \\ E-mail: gustavoborgesguastala@gmail.com \\ João Paulo Melleiro Malagutti \\ ORCID: https://orcid.org/0000-0002-9906-9758 \\ Universidade Estadual de Maringá, Brasil \\ E-mail: joaopaulomalagutti89@hotmail.com
}

\begin{abstract}
Resumo
O estudo objetivou identificar e comparar a quantidade de treinadores e treinadoras de esportes coletivos presentes na $31^{\circ}$ edição dos Jogos da Juventude do Paraná (JOJUPs) 2018. Foi realizado um levantamento através do site oficial da competição promovida pela Secretaria do Esporte e do Turismo do Paraná. Foram analisadas as súmulas de todos os jogos das modalidades: Basquetebol, Futebol, Futsal, Handebol e Voleibol, masculinas e femininas, a fim de identificar se os técnicos eram homens ou mulheres. Os resultados apontam que em um total de 740 postos possíveis de treinadores esportivos apenas 12,67\% são ocupados por mulheres, totalizando 96 mulheres, enquanto 87,03\% dos cargos são ocupados por homens, o que representa 644 homens. Dentre as modalidades, tanto nas categorias masculinas, quanto nas femininas a presença de homens como técnicos é maior, no Basquetebol, das 53 equipes $85 \%$ tinham homens como treinadores e apenas $15 \%$ eram lideradas por uma mulher; Futsal dos 190 times, 95\% eram treinados por homens, enquanto apenas 5\% eram treinadas por mulheres; Futebol, dos 128 times 96\% treinadores e apenas 4\% treinadoras; Handebol, das 50 representações, $80 \%$ tinham treinadores homens e 20\% tinham treinadoras; Voleibol, nos 64 times $84 \%$ eram treinadores homens, enquanto $16 \%$ eram treinadoras mulheres. Ao final deste trabalho foi possível constatar que ainda é muito baixo o número de mulheres em cargos de treinadoras esportivas das modalidades coletivas presentes no JOJUPs.
\end{abstract}

Palavras-chave: Mulheres; Competições; Técnicos esportivos.

\begin{abstract}
The study aimed to identify and compare the number of coaches and coaches of team sports present in the 31 st edition of the Paraná Youth Games (JOJUPs) 2018. A survey was carried out through the official website of the competition promoted by the Department of Sport and Tourism of Paraná. The summaries of all games of the modalities were analyzed: Basketball, Football, Futsal, Handball and Volleyball, male and female, in order to identify whether the coaches were men or women. The results show that out of a total of 740 possible positions for sports coaches, only $12.67 \%$ are occupied by women, totaling 96 women, while $87.03 \%$ of the positions are occupied by men, which represents 644 men. Among the modalities, both in the male and female categories, the presence of men as coaches is greater, in Basketball, $85 \%$ of the 53 teams had men as coaches and only 15\% were led by a woman; Of the 190 Futsal teams, $95 \%$ were coached by men, while only $5 \%$ were coached by women; Soccer, from 128 teams, $96 \%$ coaches and only $4 \%$ coaches; Handball, of the 50 representations, $80 \%$ had male coaches and $20 \%$ had coaches; Volleyball, in the 64 teams $84 \%$ were male coaches, while $16 \%$ were female coaches. At the end of this work, it was possible to verify that the number of women in positions of sports coaches of the collective modalities present in JOJUPs is still very low. Keywords: Women; Games; Sports coaches.
\end{abstract}




\section{Resumen}

El estudio tuvo como objetivo identificar y comparar el número de entrenadores y entrenadores de deportes colectivos presentes en la 31 edición de los Juegos Juveniles de Paraná (JOJUPs) 2018. Se realizó una encuesta a través de la página web oficial de la competencia promovida por la Concejalía de Deportes y Turismo de Paraná. Se analizaron los resúmenes de todos los partidos de las modalidades: Baloncesto, Fútbol, Fútbol Sala, Balonmano y Voleibol, masculino y femenino, con el fin de identificar si los entrenadores eran hombres o mujeres. Los resultados muestran que de un total de 740 puestos posibles para entrenadores deportivos, solo el 12,67\% están ocupados por mujeres, totalizando 96 mujeres, mientras que el $87,03 \%$ de los puestos están ocupados por hombres, lo que representa 644 hombres. Entre las modalidades, tanto en la categoría masculina como femenina, la presencia de hombres como entrenadores es mayor, en Baloncesto, el 85\% de los 53 equipos tenían hombres como entrenadores y solo el 15\% eran dirigidos por una mujer; De los 190 equipos de Futsal, el 95\% fueron entrenados por hombres, mientras que sólo el 5\% fueron entrenados por mujeres; Fútbol, de 128 equipos, 96\% entrenadores y solo 4\% entrenadores; Balonmano, de las 50 representaciones, el $80 \%$ tuvo entrenadores masculinos y el $20 \%$ tuvo entrenadores; Voleibol, en los 64 equipos el $84 \%$ eran entrenadores masculinos, mientras que el $16 \%$ eran entrenadoras. Al final de este trabajo, se pudo constatar que el número de mujeres en puestos de entrenadoras deportivas de las modalidades colectivas presentes en las JOJUPs sigue siendo muy bajo.

Palabras clave: Mujeres; Juegos; Entrenadores deportivos.

\section{Introdução}

Ser do gênero feminino e querer envolver-se no mundo esportivo nunca foi tarefa fácil. Durante os Jogos Olímpicos da Antiguidade, os homens competiam nus e as mulheres eram proibidas de assistir, sujeitas inclusive a pena de morte (Chiés, 2006). As únicas mulheres autorizadas a assistirem as competições eram as sacerdotisas, consideradas mensageiras dos deuses que traziam boa sorte aos competidores; a elas cabia a função de entregar as coroas de oliveiras aos vencedores (Chiés, 2006).

A justificativa utilizada para tal restrição imposta as mulheres era que, para os gregos, apenas os cidadãos homens tinham direito à vida pública, econômica e a gozar ou participar de eventos esportivos. Os cidadãos gregos, eram aqueles que necessariamente participavam das atividades de guerra defendendo o povo, logo, como as mulheres não realizavam tal ofício, não eram consideradas cidadãs e sua participação nos jogos era vetada (Ribeiro et al. 2013). Na sociedade grega, o papel entregue as mulheres era o de serem mães dos futuros cidadãos gregos e donas de casa (Rubio \& Simões, 1999).

É no período da revolução industrial e das grandes guerras mundiais que as mulheres começaram a participar da vida moderna, com novos empregos e mudanças de status, ocupando espaços que os homens deixaram nas indústrias, visto que estes envolviam-se em atividades militares (Oliveira et al., 2008; Ribeiro et al., 2013, Marques \& Cafeo, 2017). Neste momento, a sociedade da época começa a reconhecer as capacidades das mulheres em cumprir tarefas que homens exerciam e entram em pauta de discussão algumas questões de igualdade de gênero como: (I) o direito ao voto, (II) a independência financeira, (III) a prática esportiva, e (IV) a participação em Jogos Olímpicos (Ribeiro et al., 2013). Sobre a prática esportiva, a participação das mulheres em práticas esportivas era vedada por lei, de acordo com o Art. 54 do Decreto-Lei no 3.199 de 1941 (Brasil, 1941)

As capacidades físicas femininas, ainda consideradas como o "sexo frágil", eram questionadas pelos discursos sociais e biológicos, porém tais argumentos foram gradativamente perdendo forças (Ferreira et al., 2013). Somente em meados do século XX que as mulheres começaram a se aproximar do esporte competitivo e a partir da década de 1950 passaram a ocupar espaços nesse território (Rubio \& Simões, 1999). Desde então, o cenário esportivo tem se deparado com o envolvimento e a inserção feminina, aumentando consideravelmente a sua participação em esportes de rendimento.

Atualmente a representação das mulheres como competidoras nos jogos olímpicos se aproxima a dos homens. Durante os Jogos Olímpicos Rio 2016 as delegações nacionais contaram com a participação de 11.437 atletas sendo 6.257 dos competidores homens e 5.180 competidoras mulheres, representando 45,29\% dos atletas (Comitê Olímpico Internacional, 2018), em comparação com 4.676 atletas, 44\% do total, nos Jogos Olímpicos Londres 2012. A delegação brasileira nos Jogos Olímpicos Rio 2016, contou com a participação de 465 atletas sendo 256 homens e 209 mulheres (Comitê Olímpico Brasileiro, 2018).

Todavia, podemos pensar tal inserção no meio esportivo como um dos passos de uma longa caminhada, visto que, observamos ainda a escassez de mulheres atuando em altos cargos, principalmente naqueles com funções que envolvem 
liderança, gestão e tomada de decisão. De acordo com Ferreira et al. (2013), a maioria dos cargos de direção dos principais órgãos, sejam eles administrativos ou práticos-esportivos, dos principais clubes brasileiros, são ocupados prevalentemente por indivíduos do sexo masculino (Ferreira et al., 2013).

Alguns avanços também são registrados nos cargos de gestão em órgãos esportivos, como, por exemplo, nas comissões do Comitê Olímpico Internacional, que, no ano de 2018, teve 42,7\% das vagas nas 26 comissões ocupadas por mulheres, representando um aumento de 16,8\% na participação feminina em relação a 2017 e 98\% em relação a 2013 (Comitê Olímpico Internacional, 2018). No Comitê Olímpico Brasileiro (COB), dos 25 membros da Comissão de atletas, 11 são mulheres, porém, das 55 confederações olímpicas, reconhecidas e vinculadas do $\mathrm{COB}$, apenas a Confederação Brasileira de Ginástica é representada por uma mulher (Comitê Olímpico Brasileiro, 2021).

Internacionalmente, há pesquisas envolvendo o estudo de gênero e a representatividade em comissões técnicas de clubes esportivos, profissionais ou não, e também, em programas esportivos em universidades, demonstrando grande discrepância entre os resultados observados coletados envolvendo a diferença entre a presença de homens e mulheres (Fasting \& Pfister, 2000, Cunningham \& Sagas 2002; Shaw \& Frisby, 2006, Kilty, 2006, Reade, Rodgers \& Norman, 2009, Kamphoff, Armentrout \& Driska, 2010, Norman, 2010, Peachey \& Burton, 2011, Burton, 2015, Fasting, Sand \& Nordstrand, 2017). A nível nacional, algumas pesquisas recentes envolvendo algumas modalidades esportivas, como o caso do Handebol (Silva, Jacó \& Krahenbühl, 2021) e Futebol (Passero et al., 2020) e Basquetebol (Passero et al., 2019) destacam-se, além de estudos envolvendo mulheres e o esporte de maneira geral (Goellner, 2005, 2007, Ferreira et al., 2013, 2017, Balardin et al., 2018, Ramos, 2018, Torga, 2019).

Especificamente, no estado do Paraná, o esporte e consequentemente suas competições oficiais, são administradas e promovidas pela Secretaria de Estado da Educação e do Esporte, por intermédio da Superintendência Geral do Esporte (Secretaria da Educação e do Esporte, 2021; Paraná Esporte, 2021). Os cargos principais da gestão no estado são: Superintendente Geral do Esporte, Diretor-Presidente da Paraná Esporte, Diretor Administrativo e Financeiro, Encarregado pelo Tratamento de Dados Pessoais, Unidade de Controle Interno e Agente de Ouvidoria, Transparência e Controle Social - com cargos ocupados em sua maioria por homens (Paraná Esporte, 2021). Durante a coleta de dados, todos os cargos da Secretaria do Esporte e do Turismo órgão responsável pela competição na época - eram ocupados por homens (Secretaria do Esporte e do Turismo, 2018). Já os Escritórios Regionais do Esporte e Turismo (ERET), nas 12 sedes, 1 sub-sedes e coordenação, nenhuma mulher ocupava o cargo de chefia do escritório (Secretaria do Esporte e do Turismo, 2018).

No ambiente esportivo de maneira geral, há mais espaço para homens do que para mulheres em todos cargos, seja ele na administração, gestão, ou até mesmo nas comissões técnicas - inclusive de modalidades com maior representatividade feminina ou de times femininos - (Oliveira \& Teixeira, 2009). Seja a nível de alto rendimento ou a nível de formação esportiva, a representatividade das mulheres como técnicas é baixa; a inserção, ascensão e permanência na carreira é dificultosa. De acordo com Oliveira (2002), aquelas que tentam seguir a carreira como técnicas esportivas são frequentemente expostas a avaliações preconceituosas sobre a qualidade do seu trabalho e indagações sobre a capacidade de liderar equipes esportivas.

Apesar da importância da temática supracitada, e de estudos recentes serem se dedicarem a compreender o fenômeno da baixa representatividade feminina nos esportes de maneira geral, observou-se uma lacuna em relação a estudos que se debrucem a quantificar e a entender o fenômeno da representatividade de mulheres nas funções de treinadoras em competições oficiais, mas não necessariamente profissionais, como o caso da competição analisada. Também não foram identificados estudos com a temática em competições oficiais do estado do Paraná. Deste modo, o objetivo deste estudo foi identificar e comparar a quantidade de treinadores e treinadoras de esportes coletivos na $31^{\circ}$ edição dos Jogos da Juventude do Paraná (JOJUPs) 2018, tradicional competição que envolve os municípios do estado do Paraná e atualmente encontra-se em sua $33^{a}$ edição, competição do calendário oficial do estado do Paraná, promovida pela Secretaria do Esporte e do Turismo. 


\section{Metodologia}

Trata-se de uma pesquisa transversal, de caráter descritivo exploratório, com a intenção de proporcionar maior familiarização com a problemática em questão visando explicitá-la (Koche, 2011; Gratton \& Jones, 2015; Gil, 2019). A pesquisa exploratória ocorre onde há pouco ou nenhum conhecimento prévio de um fenômeno, havendo assim uma necessidade de uma exploração inicial antes que uma pesquisa mais específica possa ser realizada (Gratton \& Jones, 2015) e descrevendo as características de determinadas populações ou fenômenos (Gil, 2019).

A coleta de dados foi efetuada por meio de um levantamento realizado no site oficial do JOJUPs 2018. Todos os dados foram tabulados em planilha Microsoft Excel@ e exportados para o SPSS $20 \AA$, software utilizado para as análises estatísticas, posteriormente analisadas de forma descritiva. É importante destacar que a edição de 2018 do JOJUPS foi escolhida devido à falta de dados completos referentes a edição do ano de 2019 no site oficial da Secretaria de Estado da Educação e do Esporte e pelo cancelamento da edição do ano de 2020 pela pandemia do vírus Sars-cov-2 (Covid-19) (Paraná Esporte, 2020).

Foram acessadas todas as súmulas dos jogos realizados nas sedes onde ocorreram a competição; o nome e o sexo dos (as) treinadores (as) foi anotado para que o levantamento pudesse ser realizado. As modalidades utilizadas no estudo foram: Basquetebol, Futebol, Futsal, Handebol e Voleibol, tanto das equipes masculinas, quanto femininos, afim de identificar a participação das mulheres dentro das equipes como técnicas esportivas.

A competição contou com 288 cidades participantes e ocorreu em doze (12) sedes: 01 - Guaratuba; 02 - Telêmaco Borba; 03 - Uraí; 04 - Rolândia; 05 - Nova Esperança; 06 - Nova Olímpia; 07 - Ubiratã; 08 - Pranchita; 09 - Saudade do Iguaçu; 10 - Irati; 11 - Palotina e 12 - Kaloré (Secretaria do Esporte e do Turismo do Paraná, 2018). Todas as prefeituras de cidades do Paraná são convidadas a participar da competição e a enviar uma delegação que possa representar a cidade nas modalidades disponíveis no evento. Os campeões das fases regionais, disputam uma fase final, em uma nova sede.

\section{Resultados}

Com base no levantamento feito com as 288 cidades participantes dos JOJUPs 2018, que competiram nos 5 esportes (Basquetebol, Futebol, Futsal, Handebol e Voleibol) nas modalidades masculinas e femininas, foi encontrado que do total de 740 postos possíveis de treinadores, representada pela soma de todas as equipes que representaram as cidades nos esportes supracitados (conforme Tabela 1), apenas 96 destes postos eram ocupados por mulheres, correspondendo a 12,97\% do total; enquanto que os treinadores do sexo masculino ocupavam 644 vagas, o correspondente a 87,03\%, ratificando o disparate.

Tabela 1. Caracterização da amostra dos JOJUPs 2018.

\begin{tabular}{cc}
\hline Dados Descritivos & n \\
\hline Cidades participantes no JOJUPs & 288 \\
Número de equipes competidoras & 824 \\
Número total de treinadores & 740 \\
Número de treinadores do sexo masculino & 644 \\
Número de treinadoras do sexo feminino & 96 \\
Número de equipes sem treinador(a) & 84 \\
\hline
\end{tabular}

Fonte: Os autores (2021).

Ao realizar análise individualizada nas comissões técnicas de cada esporte na modalidade masculina, os achados do estudo apontaram que: no Basquetebol, das 53 equipes, 45 delas (85\%) tinham homens como treinadores e apenas 8 equipes (15\%) eram lideradas por uma mulher; Futsal dos 190 times, 183 times (95\%) eram treinados por homens, enquanto 7 equipes (5\%) eram treinadas por mulheres; Futebol, dos 128 times, encontramos 122 (96\%) treinadores e apenas 6 (4\%) treinadoras; 
Handebol, das 50 representações, 40 (80\%) tinham treinadores homens e 10 (20\%) tinham treinadoras; por fim, Voleibol, nos 64 times possíveis, 54 (84\%) eram treinadores homens, enquanto $10(16 \%)$ eram treinadoras mulheres (ver Figura 1).

Figura 1. Representação da quantidade de treinadores e treinadoras nas modalidades masculinas.

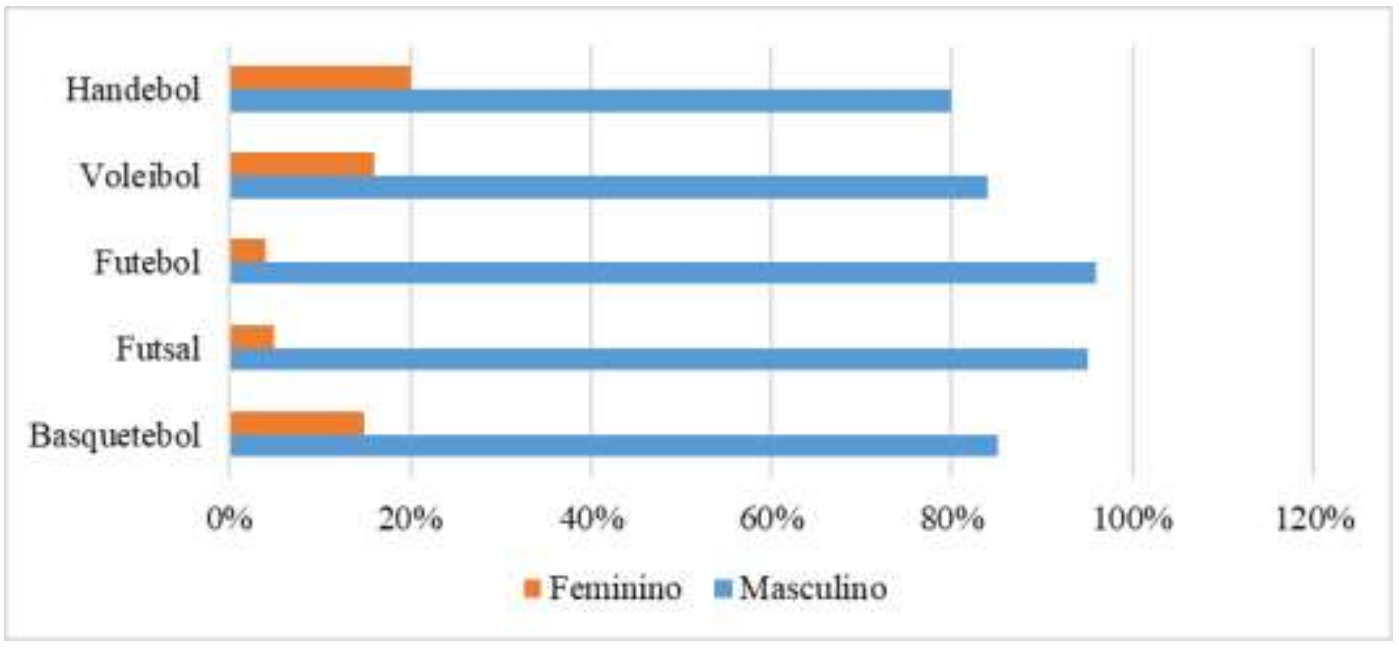

Fonte: Os autores (2021).

Já em relação a análise individualizada realizada nas comissões técnicas de cada esporte na modalidade feminina, os achados do estudo indicaram novamente uma baixa representatividade de mulheres como treinadoras. No Basquetebol, dos 5 times femininos, 4 (80\%) tinham homens como treinadores e apenas 1 (20\%) era treinado por uma mulher; Futsal, dos 131 times, $106(81 \%)$ tinham treinadores homens, enquanto apenas 25 (19\%) tinham treinadoras mulheres; Handebol, dos 38 times, 24 $(66 \%)$ tinham treinadores homens e $14(34 \%)$ tinham treinadoras mulheres; Voleibol, dos 81 times, 66 (82\%) eram treinadores homens, enquanto 15 (18\%) eram treinadoras mulheres (ver Figura 2).

Figura 2. Representação da quantidade de treinadores e treinadoras nas modalidades femininas.

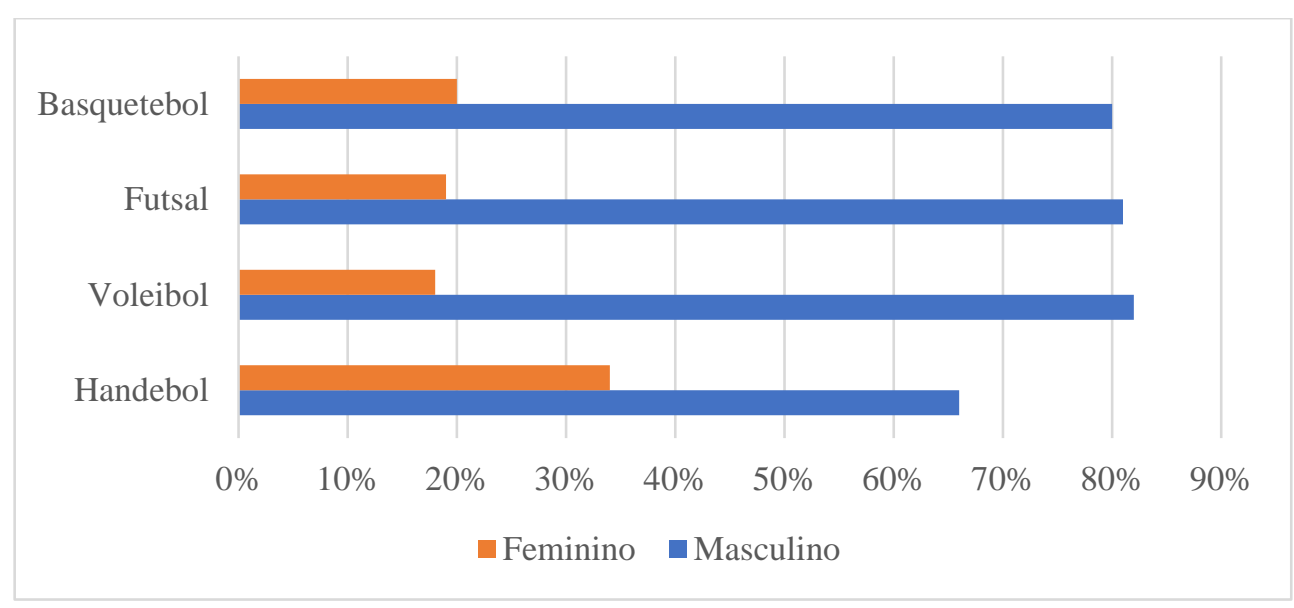

Fonte: Os autores (2021).

A figura 3 apresenta um comparativo do número de treinadores e treinadoras nas modalidades masculinas e femininas. Essa diferença se faz ainda mais presente de acordo com o esporte e a modalidade, onde apenas no handebol, na categoria feminina, o número de treinadoras mulheres apresenta um número mais significativo e aproximado em relação ao número de homens, ocupando $44 \%$ dos cargos. Nos demais esportes e modalidades, uma disparidade muito grande foi apontada. 
Figura 3. Comparação da quantidade de treinadores e treinadoras nas modalidades femininas e masculinas.

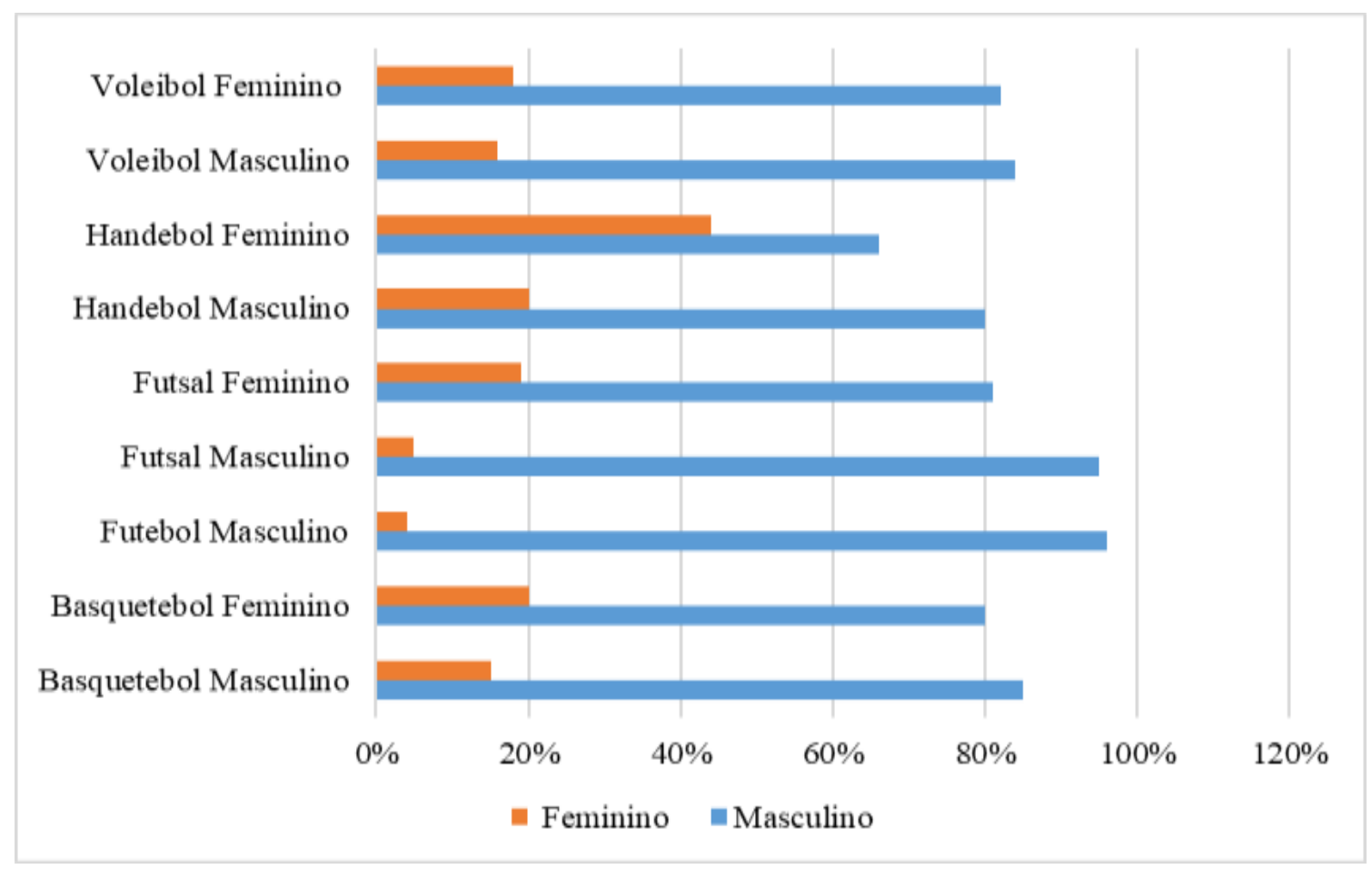

Fonte: Os autores (2021).

\section{Discussão}

Como discussão, evidenciamos que o presente estudo teve como objetivo identificar e comparar a quantidade de treinadores e treinadoras de esportes coletivos na $31^{\circ}$ edição dos JOJUPs 2018. Apesar de sensíveis avanços apresentados em diversos artigos ao longo dos anos em relação a participação das mulheres no esporte, a partir da análise realizada no JOJUPs 2018, identificamos que a realidade ainda está longe da igualdade de gênero, visto que os números apontam para uma baixa representatividade de mulheres no cargo de treinadoras das modalidades esportivas coletivas nas prefeituras do estado do Paraná, que foram representadas no JOJUPs 2018.

De acordo com o Instituto Ethos (2013), apesar de consideráveis mudanças positivas quanto a participação da mulher no mercado de trabalho e em posições hierárquicas, conforme aumentam as atribuições de liderança e comando nas funções, as mulheres são encontradas em menores proporções, indicando para um afunilamento hierárquico. Tal baixa representatividade das mulheres em cargos de comando pode ser explicada por meio da metáfora "Teto de vidro", entendida como uma barreira artificial invisível, que impede que mulheres tenham acesso a importantes cargos, como os de liderança mais elevados na hierarquia (Cunningham \& Sagas 2002, Gomes, 2012, Ferreira et al., 2013, Fasting, Sand \& Nordstrand, 2017).

A figuração por trás da metáfora "Teto de vidro" indica a ocupação feminina em posições inferiores, que visualizam posições superiores por meio da transparência do vidro, mas não conseguem alcança-los (Rocha, 2006). Esse fenômeno expõe a limitação das mulheres a ocupar a base da pirâmide, sendo excluída a sua presença em setores específicos, exclusão essa que, de acordo com Rocha (2006), não é associada a falta de habilidade e sim ao fato de simplesmente serem do sexo feminino.

A quantidade de profissionais de Educação Física do sexo feminino poderia ser um argumento para a baixa representatividade de mulheres como treinadoras, visto que, se eventualmente existisse uma quantidade maior de profissionais do sexo masculino, a tendência seria a de que a maioria dos professores que atuam com treinamento também fossem consequentemente do sexo masculino. Porém, estudos como o de Almirante (2012), quebram este argumentando pois indicam que há um equilíbrio na quantidade de profissionais do sexo masculino e feminino formados e atuando em Educação Física. 
A tabela 1 indica que das 740 vagas de treinadores, considerando todos os esportes e todas as modalidades competidas nos JOJUPs 2018, apenas 96 delas são ocupadas por mulheres, índice correspondente a 12,97\% do total de postos possíveis. Tal baixa representatividade, vai ao encontro do exposto por Ferreira et al. (2013), que indicam que nas 259 federações esportivas brasileiras, apenas 7\% dos técnicos esportivos são mulheres. Além disso, o estudo dos autores levanta que 185 destas federações não possuem mulheres registradas como treinadoras, dado muito alarmante.

Nos Jogos Pan-americanos de 2011, a proporção de mulheres integrantes da comissão técnica brasileira foi de apenas 13\% (Comitê Olímpico Brasileiro, 2018), indicando consonância com o disparate dos resultados encontrados pelo presente estudo. Para o Comitê Olímpico Internacional (COI), a promoção das mulheres nos esportes tem fundamental relevância, tanto que em 2018, com a adoção da Agenda Olímpica 2020, o COI reafirmou com a ONU e suas agências o seu compromisso de promover a igualdade de gênero (ONU Mulheres, 2015).

Desta maneira, ao compreender sua importante responsabilidade de agir em direção a igualdade de gênero, considerando-a direito humano básico de grande importância e um princípio fundamental da Carta Olímpica, o COI implementou 25 recomendações do Projeto de Revisão da Igualdade de Gênero que visam promover a não discriminação e uma maior participação das mulheres em todos os aspectos do esporte (Reuters, 2018). As recomendações giram em torno de cinco temas centrais: esporte; representação; financiamento; governança; monitoramento e comunicações (Comitê Olímpico Internacional, 2018).

Por fim, faz-se necessário apontar algumas limitações deste estudo. Por apresentar dados quantitativos e uma fotografia (visão geral da atual realidade), investigações qualitativas tornam-se necessárias para proporcionar uma melhor compreensão sobre o fenômeno. Apontamos também que, embora venha comprovado por meio dos dados coletados, o número de mulheres em comissões técnicas mostra-se discrepante dependendo da modalidade esportiva, como demonstrado neste estudo, porém em comparação com estudos internacionais a participação das mulheres em cargos técnicos e de gestão não necessariamente afiança alguma superação em relação aos últimos anos (Shaw \& Frisby, 2006, Silva, Jacó \& Krahenbühl, 2021).

\section{Conclusão}

Concluímos o presente estudo com a identificação de uma quantidade alta de treinadores do sexo masculino nos esportes coletivos representados na $31^{\circ}$ edição dos JOJUPs 2018. Foi percebida uma baixa representatividade de treinadoras do sexo feminino liderando as comissões técnicas na competição oficial da juventude paranaense. Ao comparar os dados, inclusive em modalidades competitivas femininas, foi identificada uma disparidade aguda.

Sendo assim, sugere-se como aplicação prática que entidades nacionais como o COB, ou até mesmo regionais, como a Secretaria de Estado da Educação e do Esporte, tomem medidas inspiradas nas recomendações implementadas pelo COI, com o intuito de avançar em direção a igualdade de oportunidades e condições, independente de gênero. Sugerimos ainda, a importância na elaboração e desenvolvimento de trabalhos acadêmicos/científicos com tem similar, que proporcione uma mudança inicial dos atuais cenários das mulheres treinadoras em equipes competitivas no estado do Paraná e âmbito nacional.

\section{Referências}

Almirante, C. M. O perfil dos professores de Educação Física na rede municipal de Joao Pessoa no ensino fundamental I. Dissertação (Mestrado) - Programa de Pós-Graduação em Educação, Universidade Federal da Paraíba, João Pessoa, $2012 . \quad$ Recuperado de: https://repositorio.ufpb.br/jspui/handle/tede/4691?locale=pt_BR. Acesso em: Acesso em: 24 fev. 2019.

Balardin, G. F., Voser, R. da C., Duarte, M. A., \& Mazo, J. Z. (2018). O futebol feminino no Brasil e nos Estados Unidos: semelhanças e diferenças no esporte. RBFF - Revista Brasileira de Futsal e Futebol, 10(36), 101-109. Recuperado de http://www.rbff.com.br/index.php/rbff/article/view/549.

Brasil (1941). Presidência da República. Decreto-Lei no 3.199, 14 de abril de 1941. Estabelece as bases de organização dos desportos em todo o país. Diário Oficial da União - Seção 1 - 18/4/1941, Página 7452. Disponível em: https://www2.camara.leg.br/legin/fed/declei/1940-1949/decreto-lei-3199-14-abril-1941413238-publicacaooriginal-1-pe.html. Acesso em: 10 out. 2020. 
Burton, L. J. (2015). Underrepresentation of women in sport leadership: A review of research. Sport Management Review, 18(2), 155-165. doi: https://doi.org/10.1016/j.smr.2014.02.004

Chiés, P. (2006). “Eis Quem Surge no Estádio: É Atalante!” A História das Mulheres nos Jogos Gregos. Movimento (ESEFID/UFRGS), 12(3), 99-121. DOI: https://doi.org/10.22456/1982-8918.2911.

Comitê Olímpico Brasileiro (2018). Time Brasil nos Jogos Rio 2016. Recuperado de: https://www.cob.org.br/pt/cob/time-brasil/brasil-nosjogos/participacoes/rio-2016. Acesso em: 17 jan. 2021.

Comitê Olímpico Brasileiro (2021). Integrantes da comissão de atletas. Recuperado de: https://www.cob.org.br/pt/comissao/integrantes-comissao-atletas. Acesso em: 03 jan. 2021.

Comitê Olímpico Internacional (2018). International Olympic Committee Gender Equality Review Project. International Olympic Committee. Recuperado de: https://stillmed.olympic.org/media/Document\%20Library/OlympicOrg/News/2018/03/IOC-Gender-Equality-Report-March-2018.pdf. Acesso em: 10 jan. 2019.

Cunningham, G.B., \& Sagas, M. (2002). The differential effects of human capital for male and female Division I basketball coaches. Research Quarterly for Exercise and Sport, 73(4), 489-496. DOI: https://doi.org/10.1080/02701367.2002.10609051.

Fasting, K.; Pfister, G. (2000). Female and Male Coaches in The Eyes of Female Elite Soccer Players. European Physical Education Review, 6(1), 91-110. DOI: https://doi.org/10.1177/1356336x000061001.

Fasting, K, Sand, T. S. \& Nordstrand, H. R. (2017). One of the few: the experiences of female elite-level coaches in Norwegian football. Soccer \& Society, (3), 1-17. doi: https://doi.org/10.1080/14660970.2017.1331163.

Ferreira, H., Salles, J., Mourão, L., \& Moreno, A. (2013). A baixa representatividade de mulheres como técnicas esportivas no brasil. Movimento (ESEFID/UFRGS), 19(3), 103-124. DOI: https://doi.org/10.22456/1982-8918.29087.

Ferreira, H., Salles \& J., Mourão (2015). Inserção e permanência de mulheres como treinadoras esportivas no Brasil. Journal of Physical Education, 26(1), 2129. Recuperado de: https://periodicos.uem.br/ojs/index.php/RevEducFis/article/view/22755. Acesso em: 12 jan. 2021.

Gil, A. C (2019). Métodos e técnicas de pesquisa social. $6^{\mathrm{a}}$ ed. São Paulo: Atlas.

Goellner, S. (2005). Mulher e esporte no brasil: entre incentivos e interdições elas fazem história. Pensar a Prática, 8(1), 85-100. https://doi.org/10.5216/rpp.v8i1.106.

Goellner, S. (2008). Feminismos, mulheres e esportes: questões epistemológicas sobre o fazer historiográfico. Movimento (ESEFID/UFRGS), 13(2), 173-196. DOI: https://doi.org/10.22456/1982-8918.3554.

Gomes, E. M. P. (2008). A participação das mulheres na gestão do esporte brasileiro: desafios e perspectivas. Rio de Janeiro: Quartet: FAPERJ.

Gratton, C \& Jones, I (2015). Research methods for sports studies. $3^{\mathrm{a}}$ ed. Routledge: New York.

Instituto Ethos (2010). Perfil social, racial, e de gênero das 500 maiores empresas do Brasil e suas aç̃es afirmativas - Pesquisa 2010. São Paulo: Instituto Ethos. Recuperado de: https://www.ethos.org.br/wp-content/uploads/2012/12/4Perfil-Social-Racial-e-de-G\%C3\%AAnero-das-500-Maiores-Empresas-doBrasil-e-suas-A\%C3\%A7\%C3\%B5es-Afirmativas-Pesquisa-2010.pdf. Acesso em: 04 jan. 2019.

Kamphoff, C. S., Armentrout, S. M. \& Driska, A (2010). The token female: women's experiences as division I collegiate head Coaches of men's teams. Journal of Intercollegiate Sport, 3(2), 297-15. DOI: https://doi.org/10.1123/jis.3.2.297.

Kilty, K (2006). Women in Coaching. Human Kinetics Journal, 20(2), 222-234. DOI: https://doi.org/10.1123/tsp.20.2.222. Acesso em: 23 jan. 2019.

Koche, J. C. (2011). Fundamentos de metodologia científica. Petrópolis: Vozes.

Marques, J. C. \& Cafeo, M. R. G (2017). Jogos Olímpicos do Rio 2016 e Esportes de Alto Contato na Imprensa Brasileira: a Invisibilidade da Força da Mulher em Troca de sua Beleza Física. Âncora - Revista Latino-americana de Jornalismo, 4(1), 28-51. DOI: https://doi.org/10.22478/ufpb.2359-375X.2017v4n1.35845.

Norman, L. (2010). Feeling Second Best: Elite Women Coaches' Experiences. Sociology of Sport Journal, 27(1), 89-104. DOI: https://doi.org/10.1123/ssj.27.1.89.

Oliveira, G., Cherem, E. \& Tubino, M. J.G (2008). A inserção histórica da mulher no esporte. Editora Universa. Revista Ciência e Movimento, 16(2), 118-125. DOI: http://dx.doi.org/10.18511/rbcm.v16i2.1133.

Oliveira, G. A. S. \& Teixeira, A. P. de O (2009). Trabalhando um novo caminho: A gestão esportiva. Revista Gênero, 10(1) 101-118. DOI: https://doi.org/10.22409/rg.v10i1.43.

Oliveira, G. A. S (2002). Representações sociais de mulheres técnicas sobre o comando de equipes esportivas de alto nível. Dissertação (Mestrado) - Programa de Pós-Graduação em Educação Física, Universidade Federal do Rio de Janeiro, Rio de Janeiro. Recuperado de: http://www.nuteses.temp.ufu.br/tde_busca/processaPesquisa.php?pesqExecutada=2\&id=149\&listaDetalhes\%5B\%5D=149\&processar=Processar. Acesso em: 19 out. 2018.

ONU Mulheres (2015). Comitê Olímpico Internacional $e$ ONU Mulheres firmam parceria sobre meninas e esporte. Recuperado de: http://www.onumulheres.org.br/noticias/comite-olimpico-internacional-e-onu-mulheres-fazem-parceria-para-meninas-e-esporte. Acesso em: 04 jan. 2019.

Peachey, J. W. \& Burton, L J. (2011). Male or Female Athletic Director? Exploring Perceptions of Leader Effectiveness and a (Potential) Female Leadership Advantage with Intercollegiate Athletic Directors. Sex Roles, 64(5-6), 416-425. DOI: https://doi.org/10.1007/s11199-010-9915-y. 
Paraná (2019). Lei $n^{\circ}$ 19.848, de 03 de maio de 2019. Diário Oficial do Estado do Paraná, Poder Executivo, Curitiba, PR. Recuperado de: http://www.imprensaoficial.pr.gov.br/. Acesso em: 21 jan. 2021

Paraná Esporte (20202). Nota Oficial: Cancelamento dos Jogos da Juventude do Paraná. Secretaria da Educação e do Esporte. Recuperado de: https://www.esporte.pr.gov.br/Noticia/NOTA-OFICIAL-Cancelamento-dos-Jogos-da-Juventude-do-Parana. Acesso em: 14 dez. 2020.

Paraná Esporte (2021). Quem é quem. Secretaria da Educação e do Esporte. Recuperado de em: https://www.esporte.pr.gov.br/Pagina/Quem-e-quem. Acesso em: 03 jan. 2021.

Passero, JG, Barreira, J., Calderani Junior, A., \& Galatti, LR (2019). (Des) Igualdade de Gênero: Uma Análise Longitudinal da Participação das Mulheres nas Funções de Treinadora e Arbitral na Liga Brasileira de Basquete Feminino (2010-2017). Notebooks of Sports Psychology, 19(1), 252-261. DOI: https://doi.org/10.6018/cpd.348611.

Passero, J., Barreira, J., Tamashiro, L., Scaglia, A., \& Galatti, L. (2020). Futebol de mulheres liderado por homens: uma análise longitudinal dos cargos de comissão técnica e arbitragem. Movimento (ESEFID/UFRGS), 26, e26060. DOI: https://doi.org/10.22456/1982-8918.100575.

Ramos, S. dos S (2016). Futebol e mulheres no Rio Grande do Sul: a trajetória esportiva de Eduarda Marranghello Luizelli (Duda). Dissertação (Mestrado) Programa de Pós-Graduação em Ciência do Movimento Humano, Universidade Federal do Rio Grande do Sul, Porto Alegre. Recuperado de: https://lume.ufrgs.br/handle/10183/151421. Acesso em: 06 fev. 2020.

Reade, I, Wendy, R. \& Leanne, N (2009). The Under-Representation of Women in Coaching: A Comparison of Male and Female Canadian Coaches at Low and High Levels of Coaching. International Journal of Sports Science \& Coaching, 4(4), 505-520. DOI: https://doi.org/10.1260/174795409790291439.

Reuters (2018). COI implementará 25 recomendações para promover igualdade de gêneros. Publicado em 08 de mar. de 2018. Recuperado de: https://extra.globo.com/esporte/coi-implementara-25-recomendacoes-para-promover-igualdade-de-generos-22469589. Acesso em: 04 jan. 2019.

Ribeiro, B. Z., Felipe, M. De C. R., Silva, M. R. Da \& Calvo, A. P. C (2013). Evolução histórica das mulheres nos Jogos Olímpicos. EFDeportes.com, Revista Digital, 179(1), s/p. Recuperado de: https://www.efdeportes.com/efd179/mulheres-nos-jogos-olimpicos.htm. Acesso em: 02 jan. 2019.

Rocha, C. T. da C (2006). Gênero em ação: rompendo o Teto de vidro? Novos contextos da tecnociência. Tese (Doutorado) - Programa de Pós-Graduação Interdisciplinar em Ciências Humanas, Universidade Federal de Santa Catarina, Florianópolis. Recuperado de: https://repositorio.ufsc.br/handle/123456789/88843. Acesso em: 02 fev. 2019.

Rubio, K. \& Simões, A. C (2007). De espectadoras a protagonistas - a conquista do espaço esportivo pelas mulheres. Movimento (ESEFID/UFRGS), Porto Alegre, 5(11), 50-56. DOI: https://doi.org/10.22456/1982-8918.2484.

Secretaria do Esporte e do Turismo (2018). Escritório Regional do Esporte e do Turismo. Governo do Estado do Paraná. Recuperado de: http://www.esporte.pr.gov.br. Acesso em: 08 jan. 2019.

Secretaria da Educação e do Esporte (2021). Institucional. Governo do Estado do Paraná. Recuperado de: https://www.educacao.pr.gov.br. Acesso em 19 jan. 2021.

Silva, L. A., Jacó, J. F., \& Krahenbühl, T. (2021). As (não) convocações de mulheres para cargos de liderança nas comissões técnicas no Handebol brasileiro nos anos de 2014-2020. Pensar a Prática, 24. DOI: https://doi.org/10.5216/rpp.v24.65760.

Shaw, S. \& Frisby, W. (2006). Can Gender Equity Be More Equitable?: Promoting an Alternative Frame for Sport Management Research, Education, and Practice. Journal of Sport Management, 20(4), 483-509. DOI: https://doi.org/10.1123/jsm.20.4.483.

Soares, J. F., Mourão, L., Lovisi, A., \& Novais, M. (2018). Performatividades de gênero e a abjeção dos corpos de mulheres no levantamento de peso. Movimento (ESEFID/UFRGS), 24(1), 107-118. DOI: https://doi.org/10.22456/1982-8918.70027.

Torga, M. (2019). Com a palavra, as gestoras: A trajetória de mulheres em cargos de gestão no futebol brasileiro. 2019. Dissertação (Mmestrado em Educação Física e Desportos) - Universidade Federal de Juiz de Fora, Juiz de Fora. Disponível em: https://repositorio.ufjf.br/jspui/handle/ufjf/11674. Acesso em: 16 jan. 2020 